OPEN ACCESS

Edited by:

Natalie Tzourio-Mazoyer CNRS, CEA and Université Bordeaux,

France

Reviewed by: Annick Razafimandimby, University of Caen Normandy, France Arturo Hernandez,

University of Houston, USA

*Correspondence: Stefan Elmer

s.elmer@psychologie.uzh.ch

Received: 15 April 2016 Accepted: 15 September 2016 Published: 29 September 2016

Citation:

Elmer S (2016) Broca Pars Triangularis

Constitutes a "Hub" of the

Language-Control Network during Simultaneous Language Translation.

Front. Hum. Neurosci. 10:491. doi: 10.3389/fnhum.2016.00491

\section{Broca Pars Triangularis Constitutes a "Hub" of the Language-Control Network during Simultaneous Language Translation}

\author{
Stefan Elmer* \\ Auditory Research Group Zurich, Division Neuropsychology, Institute of Psychology, University of Zurich, Zurich, Switzerland
}

Until now, several branches of research have fundamentally contributed to a better understanding of the ramifications of bilingualism, multilingualism, and language expertise on psycholinguistic-, cognitive-, and neural implications. In this context, it is noteworthy to mention that from a cognitive perspective, there is a strong convergence of data pointing to an influence of multilingual speech competence on a variety of cognitive functions, including attention, short-term- and working memory, set shifting, switching, and inhibition. In addition, complementary neuroimaging findings have highlighted a specific set of cortical and subcortical brain regions which fundamentally contribute to administrate cognitive control in the multilingual brain, namely Broca's area, the middle-anterior cingulate cortex, the inferior parietal lobe, and the basal ganglia. However, a disadvantage of focusing on group analyses is that this procedure only enables an approximation of the neural networks shared within a population while at the same time smoothing inter-individual differences. In order to address both commonalities (i.e., within group analyses) and inter-individual variability (i.e., single-subject analyses) in language control mechanisms, here I measured five professional simultaneous interpreters while the participants overtly translated or repeated sentences with a simple subject-verb-object structure. Results demonstrated that pars triangularis was commonly activated across participants during backward translation (i.e., from $L 2$ to $L 1$ ), whereas the other brain regions of the "control network" showed a strong inter-individual variability during both backward and forward (i.e., from L1 to L2) translation. Thus, I propose that pars triangularis plays a crucial role within the language-control network and behaves as a fundamental processing entity supporting simultaneous language translation.

Keywords: executive functions, simultaneous interpreters, fMRI, single-subject analyses, overt speech

\section{INTRODUCTION}

Simultaneous language translation constitutes a complex linguistic task that strongly relies on executive functions. In fact, this specific task implies attentive listening to the input language while at the same time maintaining the source information in short-term memory, articulating in a target language (working memory and language switching), controlling the output language (divided attention), and inhibiting the articulatory codes of the input language (Elmer, 2012). 
Previous structural (Elmer et al., 2011a, 2014a) and functional neuroimaging studies performed with professional simultaneous interpreters (SIs) (Rinne et al., 2000; Elmer et al., 2011b; HervaisAdelman et al., 2015a) and multilingual subjects (Price et al., 1999; Rodriguez-Fornells et al., 2006; Abutalebi and Green, 2007; Hervais-Adelman et al., 2015b), have identified Broca's area, the caudate nuclei, the middle-anterior cingulate cortex, as well as the inferior parietal lobe as being part of the language-control network. Notably, the same brain regions have also been shown to be functionally (Elmer et al., 2011b; Hervais-Adelman et al., 2015a) and structurally (Elmer et al., 2011a, 2014a) altered in professional SIs compared to multilingual control subjects. In particular, professional SIs demonstrated reduced gray matter volume in the left middle-anterior cingulate gyrus, bilateral pars triangularis, left pars opercularis, bilateral middle part of the insula, and in the left supramarginal gyrus (Elmer et al., 2014a). Interestingly, gray matter volume in left pars triangularis, right pars opercularis, middle-anterior cingulate cortex, and in the bilateral caudate nuclei has also been shown to correlate fairly well with the cumulative number of interpreting hours (Elmer et al., 2014a). In addition, SIs have previously been shown to be characterized by reduced fractional anisotropy in fiber tracts encompassing the left anterior insula, the right inferior parietal lobe, the dorsal part of the right caudate nucleus as well as the cingulum. Finally, previous fMRI studies reported a training-related reduced recruitment of the right caudate nucleus during simultaneous language translation (Hervais-Adelman et al., 2015a) as well as a displacement of attentional functions from frontal to parietal brain sites (Elmer et al., 2011b) in SIs compared to multilingual control subjects.

Certainly, it is important to mention that comparable effects have previously already been extensively described in bilinguals and multilinguals (Price et al., 1999; Abutalebi et al., 2000; Rodriguez-Fornells et al., 2002; Mechelli et al., 2004; Abutalebi and Green, 2007; Hernandez, 2009; Zou et al., 2012a,b; Della Rosa et al., 2013), leading to suggest a general organizational principle underlying language control mechanisms. Importantly, the prominent engagement of cognitive control mechanisms necessarily required to manage multiple languages with one brain has also been shown to be associated with behavioral advantages in a variety of cognitive domains, including attention (Bialystok et al., 2004; Costa et al., 2008), working memory (Morales et al., 2013), set shifting (Festman and Münte, 2013), and inhibition (Bialystok et al., 2004; Festman et al., 2010).

A main drawback of previous studies is that most of them exclusively focused on group analyses. Even though there is no doubt that group analyses constitute a powerful approach for inferring generalization of brain functions within a specific population, by using this procedure it results difficult to ensure that a particular brain region is consistently activated above threshold in each single participant. In other words, this procedure is especially powerful for estimating functional commonalities while at the same time neglecting inter-individual differences. This can be especially problematic when it comes to evaluate brain activity in small samples of subjects or even when it comes to evaluate the contribution of higher cognitive functions. In fact, function and anatomy of brain areas at the top of the hierarchical organization are more variable across individuals compared to those involved in more basic perceptual and motor processes (Gordon et al., 2015). Otherwise, singlesubject analyses have the drawback of rendering difficult the comparability of results across subjects, for example when it comes to associate activity originating from slightly different clusters within a particular brain region with the underling functions. Consequently, a combination of single-subject- and group analyses constitutes an interesting approach that enables a more holistic description of brain functions, especially in small samples of subjects.

In the current fMRI study, I combined single-subjects and group analyses, and addressed inter-individual commonalities as well as differences in the recruitment of the language-control network in five professional simultaneous interpreters while the subjects performed a simultaneous language translation task or overtly repeated simple auditory presented sentences. Based on previous work (Abutalebi and Green, 2007; Elmer et al., 2014a), statistical analyses were restricted to a specific set of a-priori defined brain regions that have repeatedly been shown to support cognitive control mechanisms (Abutalebi and Green, 2007) and to be altered as a function of interpreting training (Abutalebi and Green, 2007; Elmer et al., 2011a, 2014a), namely bilateral Broca’s area, the inferior parietal lobe, the middle-anterior cingulate cortex, the caudate nuclei, and the insula.

Since its discovery in the middle of the nineteenth century, Broca's region has attracted considerable attention, especially in the domain of speech and language processing (Price, 2000, 2012; Bookheimer, 2002; Fiebach et al., 2005; Friederici, 2006). Broca's region is situated in the ventral-posterior part of the inferior frontal gyrus and can be subdivided into a rostral and caudal part, namely pars triangularis and pars opercularis, respectively. From a histological perspective, pars opercularis is a dysgranular area characterized by a sparse pronounced fourth layer. Therefore, this brain region is often considered to be part of motor territory (Amunts et al., 1999; Anwander et al., 2007; Kelly et al., 2010) and to constitute a higher instance supporting speech processing, articulation as well as phonological processing (Eickhoff et al., 2009; Price, 2012). By contrast, pars triangularis is a granular area which has the same histological architecture as other brain regions situated in the prefrontal cortex (Amunts et al., 1999; Anwander et al., 2007; Kelly et al., 2010) and subserving higher cognitive functions (Amunts et al., 1999). Even though pars triangularis has repeatedly been associated with linguistic processes, including syntax and semantic (Thompson et al., 1999; Fiebach et al., 2005; Friederici, 2006; Tyler et al., 2011; Bornkessel-Schlesewsky and Schlesewsky, 2013; Friederici and Gierhan, 2013), its precise functional role still remains somewhat controversial.

In the last decades, the functional role of Broca's area (pars opercularis and triangularis) has fundamentally been revised. In fact, nowadays there is a growing body of evidence indicating that Broca's area is not exclusively a speech- and language-selective region but sub-serves a variety of cognitive functions (Fedorenko et al., 2012; Fedorenko, 2014). For example, Eickhoff and colleagues performed a meta-analysis of neuroimaging studies acquired during a variety of verbal fluency tasks and revealed that 
pars opercularis more likely constitutes the final stage of word retrieval from memory rather than supporting articulation per se (Eickhoff et al., 2009). Accordingly, activity in pars triangularis has previously repeatedly been observed while performing different cognitive tasks, like language switching, attention, and inhibition (Price et al., 1999; Fuster, 2001; Rodriguez-Fornells et al., 2002, 2006; Rogalsky and Hickok, 2011; Fedorenko et al., 2012; Santi and Grodzinsky, 2012). Furthermore, there is even a convergent body of data indicating that the same area supports verbal working memory functions during both single-words (Chein et al., 2002) or sentence processing (Rogalsky and Hickok, 2011), especially in high-load conditions (Caplan and Waters, 1999). Notably, since language-selective and domain-general regions are assumed to lay side by side within Broca's area (Fedorenko et al., 2012), this specific brain region constitutes the most eligible candidate for being considered as a "hub" region within the language-control network.

Since the pivotal work of Dronkers (1996) and Wise et al. (1999), the left anterior insula has repeatedly been identified as being crucially involved, among other functions (Flynn et al., 1999; Sterzer and Kleinschmidt, 2010), in articulation and phonation (Ackermann and Riecker, 2010; Kurth et al., 2010; Baldo et al., 2011), regulation of ventilation during speech production (Dronkers, 1996; Ackermann and Riecker, 2010; Baldo et al., 2011), and sensory-to-motor coupling mechanisms (Mutschler et al., 2007, 2009), the latter contributing to the transformation of phonetic representations into articulatory codes. Previous fMRI studies have reported both white- (Elmer et al., 2011a) and gray (Elmer et al., 2014a) matter changes in the left anterior insula in SIs compared to multilinguals, and the same region has been shown to be structurally altered in French subjects who learned to pronounce Persian consonants (Golestani and Pallier, 2007; Golestani et al., 2007). From an anatomical perspective, the medial border of the insula adjoins to the extreme capsule, a fiber bundle that runs to Broca's area, the planum temporale, as well as to the brain stem (Ozaki et al., 1986), and via the latter rely station, to the primary motor cortex and the cerebellum. Consequently, the insula may sub-serve the integration of information between the auditory-related cortex and the motor system by supporting sensory-motor coupling mechanisms (Mutschler et al., 2007, 2009), for example, during the adjustment of articulation through auditory feedback (Berken et al., 2015). Finally, a previous dynamic causal modeling-based meta-analysis of Eickhoff et al. (2009) provided clear evidence for a functional architecture featuring the insula in a serial position between pars opercularis and the cerebellum/basal ganglia, from where the information flow converges onto the premotor- and motor cortex. In this context, it is assumed that the left anterior insula receives information about phonetic representations from Broca's regions and the auditory-related cortex, and translates it into vocal tract motor programs (Eickhoff et al., 2009).

The caudate nuclei are richly interconnected with the prefrontal cortex via cortico-striatal loops (Leh et al., 2007). Even though these nuclei have repeatedly been associated with the control of voluntary movements (Obeso et al., 2000) and speech articulation (Eickhoff et al., 2009), recent clinical (Wang et al., 2013), and neuroimaging (Li et al., 2015) data clearly emphasize a further functional contribution of the head of caudate to language control mechanisms. In particular, the caudate nuclei have been proposed to be involved in monitoring and controlling the language in use (Crinion et al., 2006). This perspective emerges in a salient manner from a previous meta-analysis of neuroimaging data (Luk et al., 2012), where Luk and colleagues evaluated functional responses in bilinguals during voluntary language switching.

The middle-anterior part of the cingulate cortex is a heterogeneous brain region (Bush et al., 2000) underlying a variety of cognitive functions, like attention, conflict monitoring, error detection, inhibition as well as language switching mechanisms (Bush et al., 2000; Abutalebi and Green, 2007; Wang et al., 2007; Moritz-Gasser and Duffau, 2009). Currently, available data indicate functional (Abutalebi et al., 2008; Luk et al., 2012) and structural (Abutalebi et al., 2012; Zou et al., 2012 b) differences in this brain region in bilinguals compared to monolinguals or even between professional SIs and multilingual control subjects (Elmer et al., 2010, 2014a).

The inferior parietal lobe (i.e., angular and supramarginal gyrus) has previously been proposed to be part of the language control network (Abutalebi and Green, 2007) and shown to be functionally and structurally altered as a function of both bilingualism (Mechelli et al., 2004; Della Rosa et al., 2013) and language expertise (Elmer et al., 2011b, 2014a). Furthermore, in bilinguals, gray matter volume in the inferior parietal lobe was found to correlate with L2 proficiency (Mechelli et al., 2004; Della Rosa et al., 2013) as well as with age of L2 acquisition (Mechelli et al., 2004). This posterior brain region sub-serves a heterogeneity of cognitive functions including attention (Elmer et al., 2011b; Karnath and Rorden, 2012; Alho et al., 2014), working memory, and short-term memory (Buchsbaum et al., 2002; Schulze and Koelsch, 2012; Herman et al., 2013), all functions that have been documented to be influenced by language experience and expertise (Bialystok et al., 2004; Abutalebi and Green, 2007; Bialystok, 2009). Complementary findings also reliably converge to the notion that the inferior parietal lobe, especially in the left hemisphere, supports linguistic functions, and phonetic processing (Ruff et al., 2003; Turkeltaub and Coslett, 2010).

\section{MATERIALS AND METHODS}

\section{Participants}

Five professional SIs that exclusively translate from German (L2) to Italian (L1) participated in the study. In order to better address whether commonalities as well as intra-individual differences are influenced by experience and age, I explicitly selected two subjects with comparable age and number of training years (i.e., subject 4 and 5 , age $=46$ and 50, training years $=22$ ), two subjects of the same age cohort but differing in training (i.e., subject 1 and 2 , age $=31$ and 33 years, training years $=$ 4 and 8 , respectively), as well as a control subject (i.e., subject 3 , age $=38$, training years $=14$ ) differing from the other subjects regarding both age and years of training. All subjects confirmed to have a very good to excellent proficiency in the two languages tested (i.e., L1 = Italian and L2 = German) 
as well as an intact audiological status. None of the control subjects grew up in a bilingual context, all participants were consistent right-handers (Annett scores: S1 11/12; S2 12/12; S3 12/12; S4 12/12; S5 12/12; the score was calculated based on right or not right responses, none of the participants reported ambidexterity) according to Annett's questionnaire (Annett, 1970), had a comparable level of education (i.e., university degree), reported no past or current neurological, psychiatric, or neuropsychological problems, and denied illegal medication. Subjects were paid for participation, the local ethics committee (Zurich, Switzerland) approved the study, and written informed consent was obtained from all participants. Table 1 provides an overview of the autobiographical data of the five SIs investigated in the present study.

\section{Task}

In the MRI environment, subjects heard short German and Italian sentences (totally 80 for each language). All sentences consisted of a subject-verb-object structure, had a mean duration of $1.75 \mathrm{~s}$ (Italian $=1.70$; German $=1.85$ ), were matched for word frequency according to the Leipzig corpora (http:// corpora.uni-leipzig.de/), and double checked by a professional linguist (D.W.). In the present work, I deliberately choose simple discourse sentences in order to minimize interactions between cognitive load and experience while at the same time focusing on brain regions essentially involved in simultaneous language translation. During scanning, the Italian and German sentences were presented in a pseudo-randomized order, and according to a specific visual cue that was simultaneously presented with the onset of the sentences (i.e., star or cloud), the subjects were instructed to repeat them aloud (i.e., shadowing, i.e., 40 German and 40 Italian sentences) or simultaneously translate them (i.e., 40 German and 40 Italian sentences). During scanning, the participants were instructed to keep their eyes open and to focus on the fixation cross presented on the screen. The auditory stimuli were jittered with an ISI corresponding to 2-5

TABLE 1 | Overview of the autobiographical data of the participants.

\begin{tabular}{|c|c|c|c|c|c|}
\hline Subject & Age & A language & $B$ language & $C$ language & $\begin{array}{l}\text { Years of } \\
\text { training }\end{array}$ \\
\hline 1 & 31 & Italian & & $\begin{array}{l}\text { German, } \\
\text { French, } \\
\text { English }\end{array}$ & 4 \\
\hline 2 & 33 & Italian & German & $\begin{array}{l}\text { French, } \\
\text { English }\end{array}$ & 8 \\
\hline 3 & 38 & Italian & & $\begin{array}{l}\text { German, } \\
\text { French, } \\
\text { Spanish, } \\
\text { English }\end{array}$ & 14 \\
\hline 4 & 46 & Italian & $\begin{array}{l}\text { French, } \\
\text { German }\end{array}$ & English & 22 \\
\hline 5 & 50 & Italian & & $\begin{array}{l}\text { German, } \\
\text { English, } \\
\text { French }\end{array}$ & 22 \\
\hline
\end{tabular}

A language $=$ mother tongue, $B$ language $=$ foreign language (high proficiency), $\mathrm{C}$ language $=$ foreign language (good proficiency). repetition times (TRs) and presented in the context of four consecutive runs, each of them lasting about $12 \mathrm{~min}$. During scanning, the participants were instructed to press a response button when starting and finishing shadowing and translation. Table 2 provides an example of the stimulus material used.

\section{fMRI Data Acquisition and Preprocessing}

Binaural auditory stimuli were presented by a digital playback system and included a high-frequency shielded transducer system. The acoustic transmission system included a piezoelectric loudspeaker enabling the transmission of strong sound pressure levels $(105 \mathrm{~dB})$ with excellent attenuation characteristics (Jäncke et al., 2002). The approximate delivered intensity level in the scanner was about $90 \mathrm{~dB}$. These loudspeakers were embedded in tightly occlusive headphones, allowing unimpeded conduction of the stimulus with good suppression of ambient scanner noise by about $20 \mathrm{~dB}$. The headphones we used for the experiment had a frequency response ranging from 100 to $16 \mathrm{KHz}$. Additionally, noise-protection ear plugs within the loudspeakers provided an additional noise attenuation of about $15-20 \mathrm{~dB}$, resulting in a total noise attenuation of $35-40 \mathrm{~dB}$. The acoustic transmission system allowed stimulation of acoustic stimuli with relatively few distortions.

A Philips Intera 3-T whole-body MR unit (Philips Medical Systems, Best, Netherlands) equipped with an 8-channel Philips SENSE head coil was used to acquire fMRIs at the University Hospital, Zurich. Functional data were obtained from 320 wholehead scans per run using a Sensitivity Encoded (SENSE) singleshot echo-planar imaging (EPI) technique (TA/TR $=2000 \mathrm{~ms}$, time echo $=35 \mathrm{~ms}$, flip angle $=78^{\circ}$, field of view $=220 \mathrm{~mm}$, acquisition matrix $=80 \times 80,30$ transverse slices, voxel size $=$ $1.72 \times 1.72 \times 4.00 \mathrm{~mm})$.

MRI data analysis was performed by using MATLAB 2013b (Mathworks Inc., Natick, Massachusetts) and the SPM12 software package (Institute of Neurology, London, UK). All images were realigned to the first image of each run, spatially normalized into standard stereotactic MNI space (EPI template provided by the Montreal Neurological Institute), interpolated to a voxel size of $2.00 \times 2.00 \times 2.00 \mathrm{~mm}$, and spatially smoothed using a 8 -mm full-with a half-maximum Gaussian kernel.

\section{fMRI Analyses}

Statistical analysis was based on the general linear model (GLM). Due to the experimental design, event-related analyses were conducted. The standardized canonical hemodynamic response was applied to model the blood oxygen level-dependent response to each of the heard (i.e., Italian and German) and spoken (i.e., shadowing and translation) sentences. In addition, the behavioral

TABLE 2 | Example of German and Italian sentences with a subject-verb-object structure.

\begin{tabular}{lll}
\hline Subject & Verb & Objekt \\
\hline Der Mann & grüsst & eine Nachbarin \\
II maestro & assegna & un compito
\end{tabular}


responses (i.e., button press at the beginning and at the end of articulation) were modeled as events, and movement (i.e., pitch, roll, and jaw) correction parameters were modeled as multiple regressors.

On the first-level analysis, the comparisons of interest, namely L2 to L1 translation (i.e., backward translation) vs. L2 shadowing and L1 to L2 (i.e., forward translation) translation vs. L1 shadowing, were implemented as linear contrasts. The resulting set of voxel values for the contrast of interest constitutes a statistical parametric map of the single-subjects T-statistic. In the present work, I consciously abstained for contrasting L2 to L1 translation vs. L1 shadowing as well as L1 to L2 translation vs. L2 shadowing. In fact, different language inputs (i.e., L1 and L2) have an influence on the cognitive demands necessary for processing the native and non-native languages. Consequently, by maintaining the input language constant this specific confound is not present. Group analyses were performed by means of one-sample $t$-tests based on first-level single-subjects contrasts. Since the analyses were restricted (both first- and second-level) on a specific set of a-priori defined regions of interest (i.e., ROIs), all results are reported at a threshold of $p<$ 0.01 and a voxel extent threshold of 10 voxels (uncorrected). The ROIs were choosen according to previous literature on cognitive control mechanisms in bilinguals (Abutalebi and Green, 2007) and SIs (Elmer et al., 2011a, 2014a), and consisted of the following brain regions: Broca's area (pars triangularis and opercularis), middle-anterior cingulate gyrus, caudate nuclei, supramarginal and angular gyrus, and middle-anterior insula. All ROIs were added into a single, composite brain mask image and explicitly applied to restrict the statistical analysis to the voxels within this mask. The first five ROIs were taken from the functional-anatomical framework proposed by Abutalebi and Green (2007), and originated from the Harvard-Oxford cortical and subcortical structural atlases as implemented in the FSL software package (http://fsl.fmrib.ox.ac.uk/fsl/fslwiki/ Atlases). The insula was selected based on previous neuroimaging studies performed with SIs (Elmer et al., 2011a, 2014a) and also originated from the Harvard-Oxford cortical structural atlas. All ROIs were threshold at $30 \%$ probability.

\section{RESULTS}

\section{Behavioral Data}

The evaluations of the behavioral data indicated that all subjects were able to shadow and translate all sentences without problems. In addition, all participants confirmed that the task was very simple in comparison to their daily work situation as SIs. Overall, all subjects were slightly faster $\left[t_{(4)}=0.946, p=0.398\right.$, n.s.] in shadowing Italian (mean $=2.64 \mathrm{~s}, S D=0.25$ ) compared to German $($ mean $=2.70, S D=0.29)$, as well as faster in translating $\left[t_{(4)}=4.843, p=0.008\right)$ from L1 to L2 $($ mean $=2.78, S D=0.33)$ compared to the backward translation (i.e., L2 to L1, mean = $3.13, S D=0.26$ ). The longer shadowing time in German as well as the longer L2 to L1 translation time is possibly to attribute to the fact that the German sentences were overall longer than the Italian ones. Otherwise, it is even possible that the Italian mother tongue of the participants may lay at the basis of this effect.

\section{Single-Subject Analyses}

Single-subject analyses consistently revealed increased activity in left pars triangularis in all five subjects during backward translation. In addition, during the same condition results revealed a huge inter-individual variability in all other regions of the language-control network (left column of Figures 1, 2 and Table 3). By contrast, during forward translation single-subject analyses did not reveal such a huge overlap across subjects but rather high variability (right column of Figures 1, 2 and Table 4).

\section{Group Analyses}

One-sample $t$-tests of first-level contrasts revealed a significant cluster situated within left pars triangularis during backward translation (Figure 3A and Table 5). By contrast, forward translation was associated with increased activity in a region situated within the left anterior insula (Figure 3C and Table 5). These results did not change when modeling age as a covariate (Figures 3B,D and Table 5).

\section{DISCUSSION}

\section{General Discussion}

Until now, only a few studies have addressed the functional and anatomical correlates of simultaneous language translation in professional- (Rinne et al., 2000; Proverbio et al., 2004, 2009; Elmer et al., 2010, 2011a,b, 2014a,b; Elmer, 2012) and trainee SIs (Hervais-Adelman et al., 2015a) or bilinguals (Price et al., 1999; Klein et al., 2006; Hervais-Adelman et al., 2015b). Furthermore, all previous studies focused on statistical analyses at the group-level while completely neglecting inter-individual variability in the recruitment of language-control networks. A second drawback is that most of these studies used complex and variable sentence structures that pose additional demands on executive functions potentially interacting with the core processes underlying simultaneous language translation. In addition, some studies investigated bilinguals (Klein et al., 2006; Price et al., 1999; Hervais-Adelman et al., 2015b) or trainee interpreting students (Hervais-Adelman et al., 2015a) instead of professional SIs, leading to unspecific results and putative confounds. Finally, it is noteworthy to mention that some authors even measured SIs who differed in the trained language direction, leading to contamination effects and resulting in limited explanatory power (Hervais-Adelman et al., 2015a).

In the present work, I used fMRI and measured five professional SIs while the subjects performed backward- and forward simultaneous translations of simple sentences with a subject-verb-object structure or simply repeated the heard sentences (i.e., shadowing). In addition, in order to capture both the brain regions essentially involved in administrating cognitive control mechanisms (i.e., "hub" areas) as well inter-individual differences (i.e., "supportive" areas), I combined single-subjectsand group analyses. Importantly, based on previous work indicating functional differences in the processing of different languages (i.e., perception and articulation) (Kim et al., 1997; Perani et al., 1998, 2003; Paulesu et al., 2000), here I exclusively measured SIs specifically trained to perform translations from German (i.e., L2) to Italian (i.e., L1). Furthermore, in order 


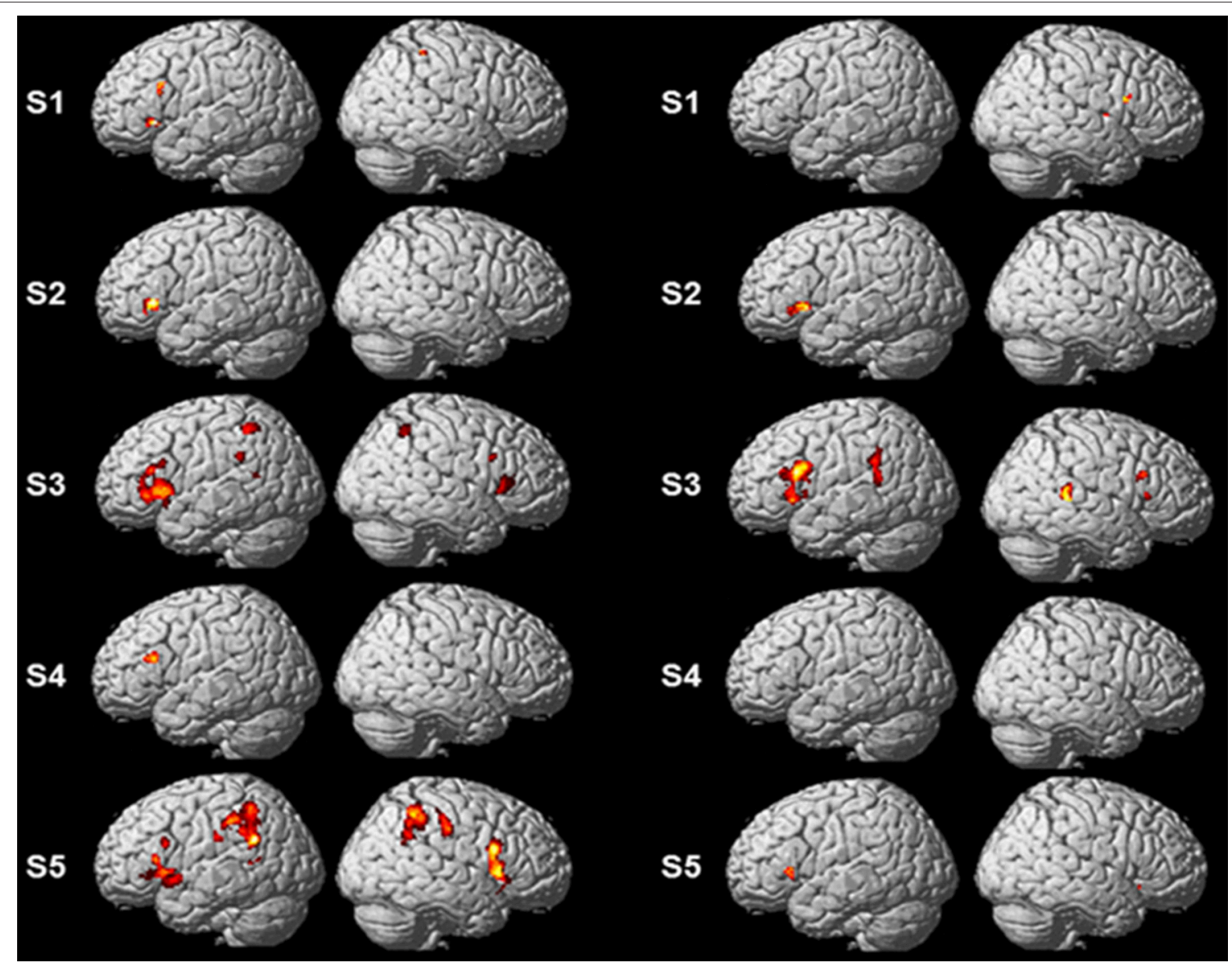

FIGURE 1 | Results of the single-subject analyses. Significant results for each subject (S1-S5) are shown on rendering surfaces for both the linear contrasts "translation L2 to L1" vs. "shadowing L2" (left side) and "translation L1 to L2" vs. "shadowing L1" (right side).

to compensate for the small sample of subjects measured, I carefully selected the participants in such a manner as to estimate a putative influence of training experience and age on brain activity. Thereby, I measured two SIs with comparable age but differing in the number of training years (i.e., 33/31 years of age and $8 / 4$ years of training, respectively), two subjects with similar age and years of training (i.e., 46/50 years of age and 22 years of training), as well as a subject situated in the middle of the sample distribution regarding age and training experience (i.e., 38 year of age and 14 years of training). Finally, it is important to mention that I consciously abstained from additionally measuring bilingual control subjects, since they are not able to perform simultaneous translations for a long time, leading to contamination effects that are driven by task difficulty, effort, and inability to perform the task.

Group analyses revealed that pars triangularis can be considered as a "hub" supporting backward language translation, whereas the left anterior insula seems to be more strongly involved in forward translation. Notably, single-subjects analyses revealed a somewhat different picture. In fact, even though the left pars triangularis was consistently activated in all five participants during backward translation, only three out of five participants showed increased activity in the insula (and only one out of them was characterized by a leftward asymmetry) during forward translation. These results lead to suggest that only pars triangularis can be considered as a "hub" region of the language-control network, whereas all other regions showing a remarkable inter-individual variability should more likely be considered as being "supportive" areas. In turn, I will discuss the functional role of these regions in more details by focusing on both commonalities as well as inter-individual variability.

\section{Functional Commonalities in Backward Translation (L2 to L1): Broca's Region}

Results demonstrated consistent and robust brain activity within pars triangularis during backward translation compared to shadowing. Since this specific activation pattern emerged in each of the five subjects as well as from the group analysis, I propose that pars triangularis constitutes the "hub" region underling simultaneous language translation. Comparable results have previously been reported by Rinne and colleagues during both backward- and forward translation of complex sentences in SIs (Rinne et al., 2000). However, in this previous work the authors used PET instead of fMRI (suboptimal spatial 


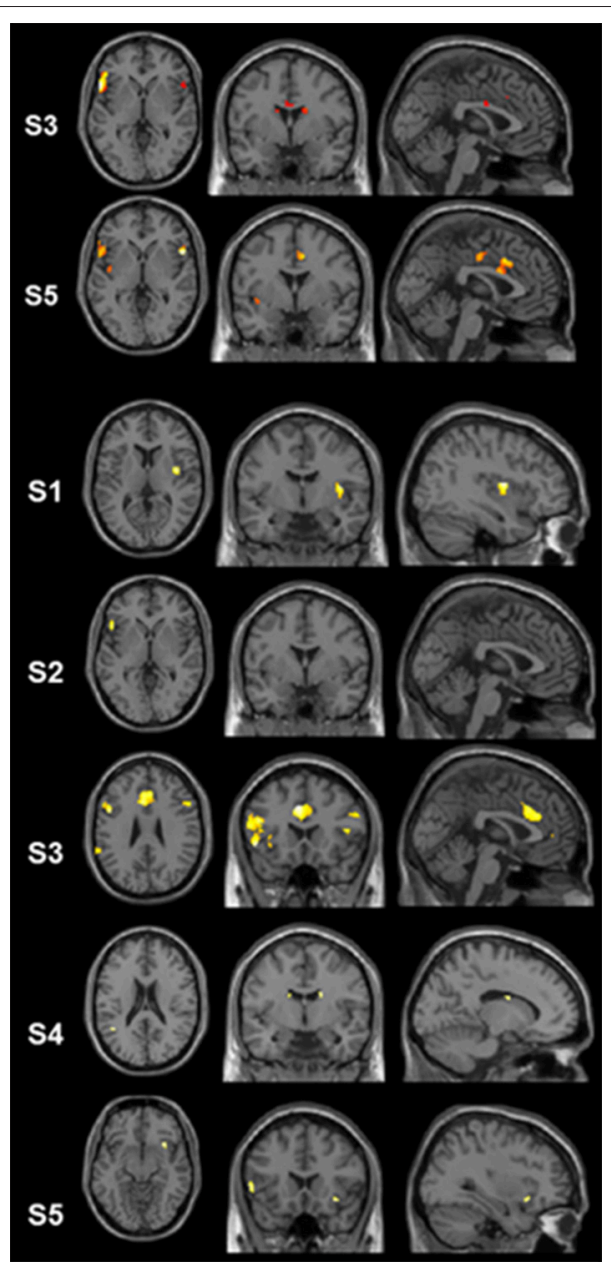

FIGURE 2 | Results of the single-subject analyses. Significant results for the linear contrasts "translation L2 to L1" vs. "shadowing L2" (first three rows, S3, S5, S1) and "translation L1 to L2" vs. "shadowing L1" (last four rows, S2-S5) are depicted on transversal (left), coronal (middle), and sagittal (rigth) brain slices. The intersecting planes correpond to the coordinates depicted in Tables 3, 4

and temporal resolution) and measured Finnish SIs specifically trained to translate in both language directions, namely from L2 to L1 as well as from L1 to L2. Most interestingly, a recent longitudinal fMRI study conducted with trainee SIs (HervaisAdelman et al., 2015a) did not reveal increased brain responses in pars triangularis at $\mathrm{T} 1$ compared to $\mathrm{T} 0$ as a function of training. However, this is not really surprising, than the control group was composed of multilinguals, a specific sample of subjects that has previously been shown to activate the same brain region during both translation at the word- (Klein et al., 1995) and sentence (Hervais-Adelman et al., 2015b) level as well as in the context of language switching (Price et al., 1999; Quaresima et al., 2001; Garbin et al., 2011).

Continuous language switching over time constitutes a fundamental cognitive operation underlying working memory functions. Consequently, I propose that pars triangularis serves as a "hub" region supporting verbal working memory functions during simultaneous language translation. Certainly, the exact operationalization of the cognitive operations involved have to be elucidated in more details, than at the moment it still remains an open question whether this regions supports language switching mechanisms per se, domain-general working memory functions, or rather some other forms of cognitive control mechanisms, like attention or inhibition (or even a combination of these functions).

A further alternative explanation is that the consistent activity revealed within pars triangularis during backward translation reflects automaticity in language switching mechanisms. This point of view is strenghtened by the fact that the translation task I used in the present work was quite simple and easy to manage for professional SIs. Furthermore, similar brain responses could not be observed during forward translation, a task that has not been explicitely trained by the SIs measured and was therefore not automatized. Finally, based on previous studies showing a relationship between grays matter volume in the left pars triangularis and the cumulative number of training hours in SIs (Elmer et al., 2014a), data are interpreted as suggesting that automatic switching mechanisms are shaped by training.

\section{Functional Commonalities in Forward Translation (L1 to L2): Left Anterior Insula}

Interestingly, even though group analyses clearly revealed that the anterior part of the left insula constitutes a common neural substrate of simultaneous language translation, this specific brain region was activated above threshold in three participants only. In addition, two out of these three subjects showed right-sided activity. The somewhat differential results between single-subject- and group analyses emphasize the importance of additionally examining functional distribution of brain activity within the single participants instead of only focusing on group statistics.

Previous work on simultaneous language interpretation has postulated that forward translation constitutes a more demanding task than backward translation (Klein et al., 1995; Rinne et al., 2000), from both cognitive- and articulatory perspectives. Therefore, I suggest that activity in the left anterior insula reflects articulatory- and cognitive operational demands while switching from L1 to L2. Based on the fact that none of the participants was a simultaneous bilingual, and on previous neuroimaging studies pointing to increased activity in brain regions supporting the motor act of speech in late- compared to early bilinguals (Frenck-Mestre et al., 2005), results are interpreted as reflecting stronger demands on articulatory- and sensory-to-motor coupling systems while translating sentences from the mother tongue into the weaker language. Certainly, future studies looking at the functional recruitment of the left anterior insula in overt speech production in subjects varying in the degree of speech competence are strictly required in order to confirm these findings.

Finally, it is important to mention that a previous metaanalysis focusing on the functional connectivity of the insula when participants were involved in active tasks (Cauda et al., 2012) revealed that the anterior part of this brain region is 
TABLE 3 | Peak maxima of each subject (S1-S5) for the contrast "translation L2 to L1" vs. "shadowing L2."

\begin{tabular}{|c|c|c|c|c|c|c|c|c|}
\hline \multirow[t]{2}{*}{ Subject } & \multirow[t]{2}{*}{$P$-value (uncorrected) } & \multirow[t]{2}{*}{$T$-value } & \multicolumn{3}{|c|}{ MNI coordinates } & \multirow[t]{2}{*}{ Hemisphere } & \multirow[t]{2}{*}{ Brain region } & \multirow[t]{2}{*}{ Cluster size } \\
\hline & & & $x$ & $y$ & $z$ & & & \\
\hline \multirow[t]{4}{*}{ S1 } & 0.001 & 3.25 & -50 & 24 & -4 & $\mathrm{~L}$ & Inferior frontal gyrus, p. Triangularis & 32 \\
\hline & 0.001 & 3.12 & -38 & 22 & -2 & $\mathrm{~L}$ & Inferior frontal gyrus, p. Triangularis & 19 \\
\hline & 0.001 & 3.02 & -54 & 18 & 30 & $\mathrm{~L}$ & Inferior frontal gyrus, p. Triangularis & 35 \\
\hline & 0.004 & 2.63 & 44 & -42 & 56 & $R$ & Supramarginal gyrus & 11 \\
\hline S2 & 0.00001 & 3.57 & -48 & 26 & 0 & $\mathrm{~L}$ & Inferior frontal gyrus, p. Triangularis & 85 \\
\hline \multirow[t]{13}{*}{ S3 } & 0.00001 & 6.7 & -56 & 16 & 0 & $\mathrm{~L}$ & Inferior frontal gyrus, p. Opercularis \& Triangularis & 543 \\
\hline & 0.00001 & 3.87 & -50 & -50 & 56 & $\mathrm{~L}$ & Supramarginal gyrus & 111 \\
\hline & 0.00001 & 3.6 & 52 & -54 & 54 & $\mathrm{R}$ & Supramarginal gyrus & 47 \\
\hline & 0.00001 & 3.51 & -42 & 18 & -4 & $\mathrm{~L}$ & Inferior frontal gyrus, p. Triangularis & 24 \\
\hline & 0.00001 & 3.36 & 52 & 14 & 32 & $\mathrm{R}$ & Inferior frontal gyrus, p. Opercularis & 26 \\
\hline & 0.00001 & 3.3 & -4 & -4 & 30 & $\mathrm{~L}$ & Middle cingulate cortex & 40 \\
\hline & 0.001 & 3.23 & -2 & 22 & 36 & $\mathrm{~L}$ & Middle-anterior cingulate cortex & 13 \\
\hline & 0.001 & 3.2 & 16 & -2 & 24 & $\mathrm{R}$ & Caudate nucleus & 37 \\
\hline & 0.001 & 3.13 & -62 & -40 & 32 & $\mathrm{~L}$ & Supramarginal gyrus & 38 \\
\hline & 0.002 & 2.89 & -16 & -18 & 24 & $\mathrm{~L}$ & Caudate nucleus & 10 \\
\hline & 0.002 & 2.85 & 54 & 20 & 2 & $\mathrm{R}$ & Inferior frontal gyrus, p. Triangularis & 103 \\
\hline & 0.003 & 2.8 & -12 & 0 & 22 & $\mathrm{~L}$ & Caudate nucleus & 10 \\
\hline & 0.004 & 2.64 & -50 & -54 & 16 & $\mathrm{~L}$ & Angular gyrus & 12 \\
\hline S4 & 0.0001 & 4 & -54 & 24 & 22 & $L$ & Inferior frontal gyrus, p. Triangularis & 66 \\
\hline \multirow[t]{14}{*}{ S5 } & 0.0001 & 5.03 & 54 & 16 & 0 & $R$ & Inferior frontal gyrus, p. Opercularis & 401 \\
\hline & 0.0001 & 4.36 & -52 & 18 & -4 & $L$ & Inferior frontal gyrus, p. Triangularis & 178 \\
\hline & 0.0001 & 4.15 & -44 & 12 & -8 & $\mathrm{~L}$ & Anterior insula & 224 \\
\hline & 0.0001 & 4.1 & 40 & -42 & 48 & $\mathrm{R}$ & Supramarginal gyrus & 292 \\
\hline & 0.0001 & 3.95 & 66 & -22 & 38 & $\mathrm{R}$ & Supramarginal gyrus & 127 \\
\hline & 0.0001 & 3.94 & -40 & -52 & 26 & $\mathrm{~L}$ & Angular gyrus & 682 \\
\hline & 0.0001 & 3.67 & -4 & 14 & 38 & $\mathrm{~L}$ & Middle-anterior cingulate cortex & 370 \\
\hline & 0.0001 & 3.34 & -62 & -24 & 30 & $\mathrm{~L}$ & Supramarginal gyrus & 42 \\
\hline & 0.001 & 3.23 & -56 & 18 & 24 & $\mathrm{~L}$ & Inferior frontal gyrus, p. Triangularis & 29 \\
\hline & 0.001 & 3.08 & 0 & -12 & 44 & $\mathrm{R}$ & Middle cingulate cortex & 80 \\
\hline & 0.001 & 3.04 & -50 & -50 & 8 & $\mathrm{~L}$ & Angular gyrus & 13 \\
\hline & 0.002 & 2.85 & 18 & -16 & 24 & $\mathrm{R}$ & Caudate nucleus & 14 \\
\hline & 0.002 & 2.84 & 58 & -52 & 38 & $\mathrm{R}$ & Supramarginal gyrus & 91 \\
\hline & 0.003 & 2.78 & 36 & 20 & -10 & $R$ & Anterior insula & 14 \\
\hline
\end{tabular}

$P<0.01$ (uncorrected).

connected with frontal, cingulate, and parietal areas, and is mostly activated by cognition. Otherwise, the posterior portion of the insula was characterized by a more local connectivity pattern and connected to sensorimotor, temporal and posterior cingulate areas and rather related to interoception, perception, and emotion (for an extensive review consider Bamiou et al., 2003).

\section{Inter-Individual Variability in Backward and Forward Translation}

Single-subject analyses clearly demonstrated a huge range of intra-individual variability in the recruitment of "supportive" areas within the language-control network. This variability is interpreted as reflecting individual strategies during simultaneous translation that are possibly driven by several factors like experience, age of commencement, as well as predisposition. In turn, I will discuss the functional-anatomical architecture of these "supportive" areas by focusing on those brain regions that have not yet been discussed in the previous section, namely the basal ganglia, the middle-anterior cingulate cortex, and the inferior parietal lobe.

\section{Caudate Nuclei}

Interestingly, there is evidence showing functional and structural differences in the caudate nuclei between bilinguals and monolinguals (van Heuven et al., 2008; Zou et al., 2012b; Abutalebi et al., 2013) as well as between professional or trainee SIs and multilingual control subjects (Elmer et al., 2011a, 2014a; Hervais-Adelman et al., 2015a). In addition, in a previous morphometric study of our group we provided evidence for a 
TABLE 4 | Peak maxima of each subject (S1-S5) for the contrast "translation L1 to L2" vs. "shadowing L1."

\begin{tabular}{|c|c|c|c|c|c|c|c|c|}
\hline \multirow[t]{2}{*}{ Subject } & \multirow[t]{2}{*}{$P$-value (uncorrected) } & \multirow[t]{2}{*}{$T$-value } & \multicolumn{3}{|c|}{ MNI coordinates } & \multirow[t]{2}{*}{ Hemisphere } & \multirow[t]{2}{*}{ Brain region } & \multirow[t]{2}{*}{ Cluster size } \\
\hline & & & $x$ & $y$ & $z$ & & & \\
\hline \multirow[t]{2}{*}{ S1 } & 0.0001 & 3.73 & 40 & -2 & 12 & $\mathrm{R}$ & Middle insula & 90 \\
\hline & 0.005 & 2.58 & 56 & 12 & 20 & $\mathrm{R}$ & Inferior frontal gyrus, p. Opercularis & 11 \\
\hline S2 & 0.0001 & 4.07 & -50 & 22 & -4 & $\mathrm{~L}$ & Inferior frontal gyrus, p. Triangularis & 70 \\
\hline \multirow[t]{10}{*}{ S3 } & 0.0001 & 3.78 & -4 & 22 & 32 & $\mathrm{~L}$ & Middle-anterior cingulate cortex & 477 \\
\hline & 0.0001 & 3.52 & -50 & 20 & -4 & $\mathrm{~L}$ & Inferior frontal gyrus, p. Triangularis & 493 \\
\hline & 0.0001 & 3.35 & 56 & -40 & 14 & $\mathrm{R}$ & Angular gyrus & 151 \\
\hline & 0.001 & 3.11 & -34 & -12 & 10 & $\mathrm{~L}$ & Middle insula & 15 \\
\hline & 0.001 & 3.05 & 44 & 22 & 10 & $\mathrm{R}$ & Inferior frontal gyrus, p. Triangularis & 20 \\
\hline & 0.001 & 2.97 & -34 & 24 & -4 & $L$ & Anterior insula & 30 \\
\hline & 0.002 & 2.97 & 38 & -18 & 14 & $\mathrm{R}$ & Posterior insula & 25 \\
\hline & 0.002 & 2.96 & -62 & -42 & 30 & $\mathrm{~L}$ & Supramarginal gyrus & 131 \\
\hline & 0.002 & 2.9 & 56 & 18 & 26 & $\mathrm{R}$ & Inferior frontal gyrus, p. Opercularis & 42 \\
\hline & 0.002 & 2.87 & 10 & 40 & 10 & $\mathrm{R}$ & Anterior cingulate cortex & 42 \\
\hline \multirow[t]{3}{*}{ S4 } & 0.001 & 3.18 & 18 & -10 & 26 & $\mathrm{R}$ & Middle cingulate cortex & 20 \\
\hline & 0.001 & 3.04 & -42 & -50 & 20 & $\mathrm{~L}$ & Angular gyrus & 15 \\
\hline & 0.003 & 2.79 & -14 & -2 & 24 & $L$ & Caudate nucleus & 12 \\
\hline \multirow[t]{2}{*}{ S5 } & 0.01 & 3.07 & -56 & 24 & 6 & $\mathrm{~L}$ & Inferior frontal gyrus, p. Triangularis & 38 \\
\hline & 0.001 & 2.89 & 34 & 18 & -12 & $\mathrm{R}$ & Anterior insula & 25 \\
\hline
\end{tabular}

$P<0.01$ (uncorrected)

relationship between gray matter volume in the bilateral caudate nuclei and the cumulative number of practice hours, leading to suggest training-related adaptations. In the present work, I only observed sporadic evidence for a contribution of the caudate nuclei to simultaneous language translation. In fact, this was only the case for two subjects during backward translation (1 subject showed bilateral and another right-lateralized activity) and for one participant during forward translation (left lateralized). Consequently, the caudate nuclei cannot be considered as a "hub" region supporting language switching and translation mechanisms. Therefore, I propose that the caudate nuclei are rather subordinated to pars triangularis and recruited depending on individual-specific cognitive and motor demands.

\section{Middle-Anterior Cingulate Cortex}

The present work did not reveal consistent activations in the middle-anterior cingulate cortex during backward- or forward or translation. In fact, during the more simple backward condition this region was only responsive in two subjects, whereas during forward translation a similar pattern emerged in three out of five subjects. Consequently, the middle-anterior cingulate cortex doesn't seem to constitute a "hub" area within the languagecontrol network, but probably rather undertakes cognitive control mechanisms during high-load sentence processing. This line of argumentation is partially supported by a recent study of Hervais-Adelman and colleagues who revealed increased activity within the cingulate cortex in trainee SIs at T1 compared to T0 (Hervais-Adelman et al., 2015a). However, the cluster was not situated within the so-called "cognitive subdivision" of the cingulum (Bush et al., 2000) but rather just beyond it. By contrast,
Rinne et al. (2000) used the same baseline condition as I used in the present study, namely shadowing, and did not revealed activity within this specific brain region at the group-level.

\section{Inferior Parietal Lobe}

In the present study, results only revealed sporadic activity within this specific brain region during both backward- (2 subjects bilaterally and one subject in the right hemisphere) and forward (one subject bilaterally and one in the right hemisphere) translation. Interestingly, none of the previous studies conducted with professional- (Rinne et al., 2000) or trainee SIs (Hervais-Adelman et al., 2015a) found distinctive activity within the inferior parietal lobe during simultaneous translation. In addition, in the context of single-words translation two previous studies reported even decreased activity (Price et al., 1999) or did not find significant activations in bilinguals (Klein et al., 1995).

\section{LIMITATIONS}

In the present work, I performed statistical analyses on a small sample of professional SIs. Even though results consistently revealed left pars triangularis activation in all five participants, the sample measured here is obviously too small for drawing ultimate conclusions about the brain regions essentially involved in supporting cognitive control. Consequently, future studies using a similar experimental approach but with larger sample size are strictly required for drawing more robust conclusions about "hub" and "supportive" areas of the language control network during simultaneous translation. In addition, it is important to 
TABLE 5 | Peak maxima of group results for the contrast "translation L2 to L1" vs. "shadowing L2" and "translation L1 to L2" vs. "shadowing L1" both with and without age as covariate.

\begin{tabular}{|c|c|c|c|c|c|c|c|c|c|}
\hline \multirow[t]{2}{*}{ Contrast } & \multirow[t]{2}{*}{ Covariate } & \multirow[t]{2}{*}{$P$-value (uncorrected) } & \multirow[t]{2}{*}{$T$-value } & \multicolumn{3}{|c|}{ MNI coordinates } & \multirow[t]{2}{*}{ Hemisphere } & \multirow[t]{2}{*}{ Brain region } & \multirow[t]{2}{*}{ Cluster size } \\
\hline & & & & $x$ & $y$ & $z$ & & & \\
\hline \multirow[t]{2}{*}{$L 2$ to $L 1$ vs. shadowing $L 2$} & None & 0.001 & 7.71 & -46 & 24 & 20 & Left & Inferior frontal gyrus, p. Triangularis & 68 \\
\hline & Age & 0.001 & 12.13 & -56 & 26 & 16 & Left & Inferior frontal gyrus, p. Triangularis & 35 \\
\hline \multirow[t]{2}{*}{ L1 to L2 vs. shadowing L1 } & None & 0.0001 & 10.11 & -30 & 22 & 6 & Left & Anterior insula & 92 \\
\hline & Age & 0.0001 & 49.63 & -30 & 24 & 4 & Left & Anterior insula & 62 \\
\hline
\end{tabular}

$P<0.01$ (uncorrected).

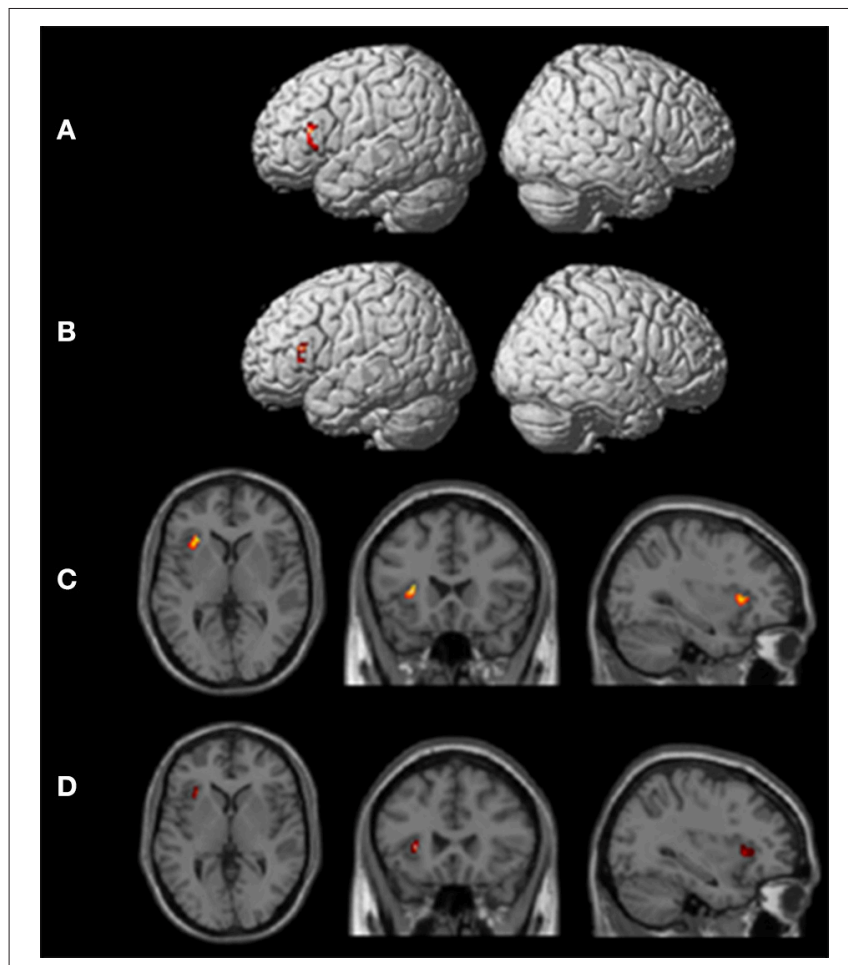

FIGURE 3 | Results of the group analyses. Significant results for the the linear contrasts "translation L2 to L1" vs. "shadowing L2" (A,B) and "translation L1 to L2" vs. "shadowing L1" (C,D) are shown on rendering surfaces (A,B) as well as on transversal (left), coronal (middle), and sagittal (rigth) brain slices (C,D). The intersecting planes correpond to the coordinates depicted in Table 5. (A,C) represent group analyses without covariates, (B,D) reflect the same contrast with age as covariate.

mention that all results have been reported with a $p$-value of 0.01 and were not corrected for multiple comparisons. Consequently, future studies using more powerful designs may be helpful in order to replicate the results reported in the present work. Finally, even though the investigation of SIs consistently translating in

\section{REFERENCES}

Abutalebi, J., Annoni, J. M., Zimine, I., Pegna, A. J., Seghier, M. L., Lee-Jahnke, H., et al. (2008). Language control and lexical competition in bilinguals: an event-related fMRI study. Cereb. Cortex 18, 1496-1505. doi: 10.1093/cercor/b hm182 a solely language direction constitutes a fruitful approach for future research, this approach has the shortcoming of putative language-specific contaminations.

\section{CONCLUSIONS}

In the present work, I tried to use an alternative approach and conjointly focused on group- and single-subjects analyses in order to disentangle "hub" and "supportive" areas of the language-control network during simultaneous language translation. Results indicated that only left pars triangularis was consistently activated across subjects. Consequently, results are interpreted as suggesting that only pars triangularis can be considered as a "hub" region, whereas all other areas of the control network are more likely susceptible to interindividual variability and should therefore rather be considered as "supportive" regions. These results challenge previous models of language control mechanisms and may lay the base for a redefinition of the language-control network. The next important step will be to focus on functional connectivity between pars triangularis and the other areas of the control network in large samples of subjects in order to better comprehend the hierarchical dynamic interplay between "hub" and "supportive" areas.

\section{AUTHOR CONTRIBUTIONS}

SE designed the study, performed the fMRI measurement, evaluated the data, and drafted the manuscript.

\section{ACKNOWLEDGMENTS}

This research was supported by the Swiss National Science Foundation (SNF, grant nr. 320030-120661 and grant nr. 462341-05 to LJ). I would like to thank Prof. Lutz Jäncke for the infrastructure and the financial support as well as Dr. Dorothea Weniger for a careful inspection of the stimulus material.

Abutalebi, J., Della Rosa, P. A., Ding, G., Weekes, B., Costa, A., and Green, D. W (2013). Language proficiency modulates the engagement of cognitive control areas in multilinguals. Cortex 49, 905-911. doi: 10.1016/j.cortex.2012.08.018

Abutalebi, J., Della Rosa, P. A., Green, D. W., Hernandez, M., Scifo, P., Keim, R., et al. (2012). Bilingualism tunes the anterior cingulate cortex for conflict monitoring. Cereb. Cortex 22, 2076-2086. doi: 10.1093/cercor/bhr287 
Abutalebi, J., and Green, D. (2007). Bilingual language production: the neurocognition of language representation and control. J. Neurolinguistics 20, 242-275. doi: 10.1016/j.jneuroling.2006.10.003

Abutalebi, J., Miozzo, A., and Cappa, S. F. (2000). Do subcortical structures control 'language selection' in polyglots? Evidence from pathological language mixing. Neurocase 6, 51-56. doi: 10.1093/neucas/6.1.51

Ackermann, H., and Riecker, A. (2010). The contribution(s) of the insula to speech production: a review of the clinical and functional imaging literature. Brain Struct. Funct. 214, 419-433. doi: 10.1007/s00429-010-0257-x

Alho, K., Rinne, T., Herron, T. J., and Woods, D. L. (2014). Stimulusdependent activations and attention-related modulations in the auditory cortex: a meta-analysis of fMRI studies. Hear. Res. 307, 29-41. doi: 10.1016/j.heares.2013.08.001

Amunts, K., Schleicher, A., Bürgel, U., Mohlberg, H., Uylings, H. B. M., and Zilles, K. (1999). Broca's region revisited: cytoarchitecture and intersubject variability. J. Comp. Neurol. 412, 319-341.

Annett, M. (1970). A classification of hand preference by association analysis. $\mathrm{Br}$. J. Psychol. 61, 303-321. doi: 10.1111/j.2044-8295.1970.tb01248.x

Anwander, A., Tittgemeyer, M., von Cramon, D. Y., Friederici, A. D., and Knösche, T. R. (2007). Connectivity-based parcellation of Broca's area. Cereb. Cortex 17, 816-825. doi: 10.1093/cercor/bhk034

Baldo, J. V., Wilkins, D. P., Ogar, J., Willock, S., and Dronkers, N. F. (2011). Role of the precentral gyrus of the insula in complex articulation. Cortex 47, 800-807. doi: 10.1016/j.cortex.2010.07.001

Bamiou, D. E., Musiek, F. E., and Luxon, L. M. (2003). The insula (Island of Reil) and its role in auditory processing literature review. Brain Res. Rev. 42, 143-154. doi: 10.1016/S0165-0173(03)00172-3

Berken, J. A., Gracco, V. L., Chen, J. K., and Klein, D. (2015). The timing of language learning shapes brain structure associated with articulation. Brain Struct. Funct. 221, 3591-3600. doi: 10.1007/s00429-015-1121-9

Bialystok, E. (2009). Bilingualism: the good, the bad, and the indifferent. Bilingualism Lang. Cogn. 12, 3-11. doi: 10.1017/S1366728908003477

Bialystok, E., Craik, F. I. M., Klein, R., and Viswanathan, M. (2004). Bilingualism, aging, and cognitive control: evidence from the Simon task. Psychol. Aging 19, 290-303. doi: 10.1037/0882-7974.19.2.290

Bookheimer, S. (2002). Functional MRI of language: new approaches to understanding the cortical organization of semantic processing. Annu. Rev. Neurosci. 25, 151-188. doi: 10.1146/annurev.neuro.25.112701.1 42946

Bornkessel-Schlesewsky, I., and Schlesewsky, M. (2013). Reconciling time, space and function: a new dorsal-ventral stream model of sentence comprehension. Brain Lang. 125, 60-76. doi: 10.1016/j.bandl.2013.01.010

Buchsbaum, B., Hickok, G., Humphries, C., and Okada, K. (2002). Working memory for music and speech: an FMRI study. J. Cogn. Neurosci. 139.

Bush, G., Luu, P., and Posner, M. I. (2000). Cognitive and emotional influences in anterior cingulate cortex. Trends Cogn. Sci. 4, 215-222. doi: 10.1016/S13646613(00)01483-2

Caplan, D., and Waters, G. S. (1999). Verbal working memory and sentence comprehension. Behav. Brain Sci. 22, 77-94. doi: 10.1017/S0140525X990 01788

Cauda, F., Costa, T., Torta, D. M. E., Sacco, K., D’Agata, F., Duca, S., et al. (2012). Meta-analytic clustering of the insular cortex Characterizing the metaanalytic connectivity of the insula when involved in active tasks. Neuroimage 62, 343-355. doi: 10.1016/j.neuroimage.2012.04.012

Chein, J. M., Fissell, K., Jacobs, S., and Fiez, J. A. (2002). Functional heterogeneity within Broca's area during verbal working memory. Physiol. Behav. 77, 635-639. doi: 10.1016/S0031-9384(02)00899-5

Costa, A., Hernandez, M., and Sebastián-Gallés, N. (2008). Bilingualism aids conflict resolution: evidence from the ANT task. Cognition 106, 59-86. doi: 10.1016/j.cognition.2006.12.013

Crinion, J., Turner, R., Grogan, A., Hanakawa, T., Noppeney, U., Devlin, J. T., et al. (2006). Language control in the bilingual brain. Science 312, 1537-1540. doi: $10.1126 /$ science. 1127761

Della Rosa, P. A., Videsott, G., Borsa, V. M., Canini, M., Weekes, B. S., Franceschini, R., et al. (2013). A neural interactive location for multilingual talent. Cortex 49, 605-608. doi: 10.1016/j.cortex.2012.12.001

Dronkers, N. F. (1996). A new brain region for coordinating speech articulation. Nature 384, 159-161. doi: 10.1038/384159a0
Eickhoff, S. B., Heim, S., Zilles, K., and Amunts, K. (2009). A systems perspective on the effective connectivity of overt speech production. Mov. Disord. 24:S187. doi: 10.1016/s1053-8119(09)70789-x

Elmer, S. (2012). The investigation of simultaneous interpreters as an alternative approach to address the signature of multilingual speech processing. $Z$. Neuropsychol. 23, 105-116. doi: 10.1024/1016-264X/a000068

Elmer, S., Hänggi, J., and Jäncke, L. (2014a). Processing demands upon cognitive, linguistic, and articulatory functions promote grey matter plasticity in the adult multilingual brain: insights from simultaneous interpreters. Cortex 54, 179-189. doi: 10.1016/j.cortex.2014.02.014

Elmer, S., Hänggi, J., Meyer, M., and Jäncke, L. (2011a). Differential language expertise related to white matter architecture in regions subserving sensorymotor coupling, articulation, and interhemispheric transfer. Hum. Brain Mapp. 32, 2064-2074. doi: 10.1002/hbm.21169

Elmer, S., Klein, C., Kühnis, J., Liem, F., Meyer, M., and Jäncke, L. (2014b). Music and language expertise influence the categorization of speech and musical sounds: behavioral and electrophysiological measurements. J. Cogn. Neurosci. 26, 2356-2369. doi: 10.1162/jocn_a_00632

Elmer, S., Meyer, M., and Jancke, L. (2010). Simultaneous interpreters as a model for neuronal adaptation in the domain of language processing. Brain Res. 1317, 147-156. doi: 10.1016/j.brainres.2009.12.052

Elmer, S., Meyer, M., Marrama, L., and Jäncke, L. (2011b). Intensive language training and attention modulate the involvement of fronto-parietal regions during a non-verbal auditory discrimination task. Eur. J. Neurosci. 34, 165-175. doi: $10.1111 / j .1460-9568.2011 .07728 . x$

Fedorenko, E. (2014). The role of domain-general cognitive control in language comprehension. Front. Psychol. 5:335. doi: 10.3389/fpsyg.2014.00335

Fedorenko, E., Duncan, J., and Kanwisher, N. (2012). Language-selective and domain-general regions lie side by side within broca's area. Curr. Biol. 22, 2059-2062. doi: 10.1016/j.cub.2012.09.011

Festman, J., and Münte, T. (2013). Cognitive control in Russian-German bilinguals. Front. Psychol. 3:115. doi: 10.3389/fpsyg.2012.00115

Festman, J., Rodriguez-Fornells, A., and Münte, T. F. (2010). Individual differences in control of language interference in late bilinguals are mainly related to general executive abilities. Behav. Brain Funct. 1-12. doi: 10.1186/17449081-6-5

Fiebach, C. J., Schlesewsky, M., Lohmann, G., von Cramon, D. Y., and Friederici, A. D. (2005). Revisiting the role of Broca's area in sentence processing: syntactic integration versus syntactic working memory. Hum. Brain Mapp. 24, 79-91. doi: 10.1002/hbm.20070

Flynn, F. G., Benson, D. F., and Ardila, A. (1999). Anatomy of the insula functional and clinical correlates. Aphasiology 13, 55-78. doi: 10.1080/026870 399402325

Frenck-Mestre, C., Anton, J. L., Roth, M., Vaid, J., and Viallet, F. (2005). Articulation in early and late bilinguals' two languages: evidence from functional magnetic resonance imaging. Neuroreport 16, 761-765. doi: 10.1097/00001756-200505120-00021

Friederici, A. D. (2006). Broca's area and the ventral premotor cortex in language: functional differentiation and specificity. Cortex 42, 472-475. doi: 10.1016/S0010-9452(08)70380-0

Friederici, A. D., and Gierhan, S. M. E. (2013). The language network. Curr. Opin. Neurobiol. 23, 1-5. doi: 10.1016/j.conb.2012.10.002

Fuster, J. M. (2001). The prefrontal cortex - An update: time is of the essence. Neuron 30, 319-333. doi: 10.1016/S0896-6273(01)00285-9

Garbin, G., Costa, A., Sanjuan, A., Forn, C., Rodriguez-Pujadas, A., Ventura, N., et al. (2011). Neural bases of language switching in high and early proficient bilinguals. Brain Lang. 119, 129-135. doi: 10.1016/j.bandl.2011. 03.011

Golestani, N., Molko, N., Dehaene, S., LeBihan, D., and Pallier, C. (2007). Brain structure predicts the learning of foreign speech sounds. Cereb. Cortex 17, 575-582. doi: 10.1093/cercor/bhk001

Golestani, N., and Pallier, C. (2007). Anatomical correlates of foreign speech sound production. Cereb. Cortex 17, 929-934. doi: 10.1093/cercor/bhl003

Gordon, E. M., Laumann, T. O., Adeyemo, B., and Petersen, S. E. (2015). Individual variability of the system-level organization of the human brain. Cereb. Cortex. doi: 10.1093/cercor/bhv239

Herman, A. B., Houde, J. F., Vinogradov, S., and Nagarajan, S. S. (2013). Parsing the phonological loop: activation timing in the dorsal speech stream 
determines accuracy in speech reproduction. J. Neurosci. 33, 5439-5453. doi: 10.1523/JNEUROSCI.1472-12.2013

Hernandez, A. E. (2009). Language switching in the bilingual brain: what's next? Brain Lang. 109, 133-140. doi: 10.1016/j.bandl.2008.12.005

Hervais-Adelman, A., Moser-Mercer, B., and Golestani, N. (2015a). Brain functional plasticity associated with the emergence of expertise in extreme language control. Neuroimage 114, 264-274. doi: 10.1016/j.neuroimage. 2015.03.072

Hervais-Adelman, A., Moser-Mercer, B., Michel, C. M., and Golestani, N. (2015b). fMRI of simultaneous interpretation reveals the neural basis of extreme language control. Cereb. Cortex 25, 4727-4739. doi: 10.1093/cercor/bhu158

Jäncke, L., Wüstenberg, T., Scheich, H., and Heinze, H. J. (2002). Phonetic perception and the temporal cortex. Neuroimage 15, 733-746. doi: 10.1006/nimg.2001.1027

Karnath, H. O., and Rorden, C. (2012). The anatomy of spatial neglect. Neuropsychologia 50, 1010-1017. doi: 10.1016/j.neuropsychologia.2011.06.027

Kelly, C., Uddin, L. Q., Shehzad, Z., Margulies, D. S., Castellanos, F. X., Milham, M. P., et al. (2010). Broca's region: linking human brain functional connectivity data and non-human primate tracing anatomy studies. Eur. J. Neurosci. 32, 383-398. doi: 10.1111/j.1460-9568.2010.07279.x

Kim, K. H. S., Relkin, N. R., Lee, K. M., and Hirsch, J. (1997). Distinct cortical areas associated with native and second languages. Nature 388, 171-174.

Klein, D., Milner, B., Zatorre, R. J., Meyer, E., and Evans, A. C. (1995). The neural substrates underlying word generation - a bilingual functional-imaging study. Proc. Natl. Acad. Sci. U.S.A. 92, 2899-2903.

Klein, D., Zatorre, R. J., Chen, J. K., Milner, B., Crane, J., Belin, P., et al. (2006). Bilingual brain organization: a functional magnetic resonance adaptation study. Neuroimage 31, 366-375. doi: 10.1016/j.neuroimage.2005.12.012

Kurth, F., Zilles, K., Fox, P. T., Laird, A. R., and Eickhoff, S. B. (2010). A link between the systems: functional differentiation and integration within the human insula revealed by meta-analysis. Brain Struct. Funct. 214, 519-534. doi: 10.1007/s00429-010-0255-z

Leh, S. E., Ptito, A., Chakravarty, M. M., and Strafella, A. P. (2007). Fronto-striatal connections in the human brain: a probabilistic diffusion tractography study. Neurosci. Lett. 419, 113-118. doi: 10.1016/j.neulet.2007.04.049

Li, L., Abutalebi, J., Zou, L. J., Yan, X., Liu, L. F., Feng, X. X., et al. (2015). Bilingualism alters brain functional connectivity between "control" regions and "language" regions: evidence from bimodal bilinguals. Neuropsychologia 71, 236-247. doi: 10.1016/j.neuropsychologia.2015.04.007

Luk, G., Green, D. W., Abutalebi, J., and Grady, C. (2012). Cognitive control for language switching in bilinguals: a quantitative meta-analysis of functional neuroimaging studies. Lang. Cogn. Process. 27, 1479-1488. doi: 10.1080/01690965.2011.613209

Mechelli, A., Crinion, J. T., Noppeney, U., O’Doherty, J., Ashburner, J., Frackowiak, R. S., et al. (2004). Structural plasticity in the bilingual brain - Proficiency in a second language and age at acquisition affect grey-matter density. Nature 431:757.doi: $10.1038 / 431757$ a

Morales, J., Calvo, A., and Bialystok, E. (2013). Working memory development in monolingual and bilingual children. J. Exp. Child Psychol. 114, 187-202. doi: 10.1016/j.jecp.2012.09.002

Moritz-Gasser, S., and Duffau, H. (2009). Cognitive processes and neural basis of language switching: proposal of a new model. Neuroreport 20, 1577-1580. doi: 10.1097/WNR.0b013e328333907e

Mutschler, I., Schulze-Bonhage, A., Glauche, V., Demandt, E., Speck, O., and Ball, T. (2007). A rapid sound-action association effect in human insular cortex. PLoS ONE 2:e259. doi: 10.1371/journal.pone.0000259

Mutschler, I., Wieckhorst, B., Kowalevski, S., Derix, J., Wentlandt, J., SchulzeBonhage, A., et al. (2009). Functional organization of the human anterior insular cortex. Neurosci. Lett. 457, 66-70. doi: 10.1016/j.neulet.2009.03.101

Obeso, J. A., Rodriguez-Oroz, M. C., Rodriguez, M., Lanciego, J. L., Artieda, J., Gonzalo, N., et al. (2000). Pathophysiology of the basal ganglia in Parkinson's disease. Trends Neurosci. 23, S8-S19. doi: 10.1016/S1471-1931(00)00028-8

Ozaki, I., Baba, M., Narita, S., Matsunaga, M., and Takebe, K. (1986). Pure dysarthria due to anterior internal capsule and-or corona radiata infarction a report of 5 cases. J. Neurol. Neurosurg. Psychiatry 49, 1435-1437.

Paulesu, E., McCrory, E., Fazio, F., Menoncello, L., Brunswick, N., Cappa, S. F., et al. (2000). A cultural effect on brain function. Nat. Neurosci. 3, 91-96. doi: $10.1038 / 71163$
Perani, D., Abutalebi, J., Paulesu, E., Brambati, S., Scifo, P., Cappa, S. F., et al. (2003). The role of age of acquisition and language usage in early, highproficient bilinguals: an fMRI study during verbal fluency. Hum. Brain Mapp. 19, 170-182. doi: 10.1002/hbm.10110

Perani, D., Paulesu, E., Galles, N. S., Dupoux, E., Dehaene, S., Bettinardi, V., et al. (1998). The bilingual brain - Proficiency and age of acquisition of the second language. Brain 121, 1841-1852.

Price, C. J. (2000). The anatomy of language: contributions from functional neuroimaging. J. Anat. 197, 335-359. doi: 10.1046/j.1469-7580.2000. 19730335.x

Price, C. J. (2012). A review and synthesis of the first 20 years of PET and fMRI studies of heard speech, spoken language and reading. Neuroimage 62, 816-847. doi: $10.1016 /$ j.neuroimage.2012.04.062

Price, C. J., Green, D. W., and von Studnitz, R. (1999). A functional imaging study of translation and language switching. Brain 122, 2221-2235.

Proverbio, A. M., Adorni, R., and Zani, A. (2009). Inferring native language from early bio-electrical activity. Biol. Psychol. 80, 52-63. doi: 10.1016/j.biopsycho. 2008.02.006

Proverbio, A. M., Leoni, G., and Zani, A. (2004). Language switching mechanisms in simultaneous interpreters: an ERP study. Neuropsychologia 42, 1636-1656. doi: 10.1016/j.neuropsychologia.2004.04.013

Quaresima, V., Colier, W. N. J. M., Van der Sluijs, M., Menssen, J., and Ferrari, M. (2001). A functional near-infrared imaging study of translation and language switching. Neuroimage 13:S590. doi: 10.1016/s1053-8119(01)91933-0

Rinne, J. O., Tommola, J., Laine, M., Krause, B. J., Schmidt, D., Kaasinen, V., et al. (2000). The translating brain: cerebral activation patterns during simultaneous interpreting. Neurosci. Lett. 294, 85-88. doi: 10.1016/s0304-3940(00)01540-8

Rodriguez-Fornells, A., Balaguer, R. D., and Munte, T. F. (2006). Executive control in bilingual language processing. Lang. Learn. 56, 133-190. doi: 10.1111/j.14679922.2006.00359.x

Rodriguez-Fornells, A., Rotte, M., Heinze, H. J., Nösselt, T., and Münte, T. F. (2002). Brain potential and functional MRI evidence for how to handle two languages with one brain. Nature 415, 1026-1029. doi: 10.1038/4151 $026 \mathrm{a}$

Rogalsky, C., and Hickok, G. (2011). The role of broca's area in sentence comprehension. J. Cogn. Neurosci. 23, 1664-1680. doi: 10.1162/jocn.2010. 21530

Ruff, S., Marie, N., Celsis, P., Cardebat, D., and Démonet, J. F. (2003). Neural substrates of impaired categorical perception of phonemes in adult dyslexics: an fMRI study. Brain Cogn. 53, 331-334. doi: 10.1016/S0278-2626(03) 00137-4

Santi, A., and Grodzinsky, Y. (2012). Broca's area and sentence comprehension: a relationship parasitic on dependency, displacement or predictability? Neuropsychologia 50, 821-832. doi: 10.1016/j.neuropsychologia.2012.01.017

Schulze, K., and Koelsch, S. (2012). Working memory for speech and music. Ann. N. Y. Acad. Sci. 1252, 229-236. doi: 10.1111/j.1749-6632.2012.06447.x

Sterzer, P., and Kleinschmidt, A. (2010). Anterior insula activations in perceptual paradigms: often observed but barely understood. Brain Struct. Funct. 214, 611-622. doi: 10.1007/s00429-010-0252-2

Thompson, C. K., Tait, M. E., Ballard, K. J., and Fix, S. C. (1999). Agrammatic aphasic subjects' comprehension of subject and object extracted Wh questions. Brain Lang. 67, 169-187.

Turkeltaub, P. E., and Coslett, H. B. (2010). Localization of sublexical speech perception components. Brain Lang. 114, 1-15. doi: 10.1016/j.bandl. 2010.03.008

Tyler, L. K., Marslen-Wilson, W. D., Randall, B., Wright, P., Devereux, B. J., Zhuang, J., et al. (2011). Left inferior frontal cortex and syntax: function, structure and behaviour in patients with left hemisphere damage. Brain 134, 415-431. doi: 10.1093/brain/awq369

van Heuven, W. J. B., Schriefers, H., Dijkstra, T., and Hagoort, P. (2008). Language conflict in the bilingual brain. Cereb. Cortex 18, 2706-2716. doi: 10.1093/cercor/bhn030

Wang, X., Wang, Y. Y., Jiang, T., Wang, Y. Z., and Wu, C. X. (2013). Direct evidence of the left caudate's role in bilingual control: an intra-operative electrical stimulation study. Neurocase 19, 462-469. doi: 10.1080/13554794. 2012.701635

Wang, Y. P., Xue, G., Chen, C. S., Xue, F., and Dong, Q. (2007). Neural bases of asymmetric language switching in second-language learners: an 
ER-fMRI study. Neuroimage 35, 862-870. doi: 10.1016/j.neuroimage.2006. 09.054

Wise, R. J. S., Greene, J., Büchel, C., and Scott, S. K. (1999). Brain regions involved in articulation. Lancet 353, 1057-1061.

Zou, L. J., Abutalebi, J., Zinszer, B., Yan, X., Shu, H., Peng, D. L., et al. (2012a). Second language experience modulates functional brain network for the native language production in bimodal bilinguals. Neuroimage 62, 1367-1375. doi: 10.1016/j.neuroimage.2012.05.062

Zou, L. J., Ding, G. S., Abutalebi, J., Shu, H., and Peng, D. L. (2012b). Structural plasticity of the left caudate in bimodal bilinguals. Cortex 48, 1197-1206. doi: 10.1016/j.cortex.2011.05.022
Conflict of Interest Statement: The author declares that the research was conducted in the absence of any commercial or financial relationships that could be construed as a potential conflict of interest.

Copyright (c) 2016 Elmer. This is an open-access article distributed under the terms of the Creative Commons Attribution License (CC BY). The use, distribution or reproduction in other forums is permitted, provided the original author(s) or licensor are credited and that the original publication in this journal is cited, in accordance with accepted academic practice. No use, distribution or reproduction is permitted which does not comply with these terms. 